BrRkOWIT\% L.. $\approx$ GRIEN, J A. The timulus qualities of the scapegoat. Journal of Abnormal \& Social Journat of Abnormal

BERKOWTZ. L.. GREEN, J. A., \& IACAULAY, J. R. Hostility catharsis as the reduction of emotional tension. Psychiatry, 1962, 25, 23-31.

BERKOWITZ, L.. \& LE PAGE, A. Weapons as aggression-eliciting stimuli. Journal of Personality \& Social Psychology, 1967, 7 202-207.

BUSS, A. The psychology of aggression New York: Wiley, 1961.

COWEN, D., LANDES, J., \& SCHAET, D. The effects of mild frustration on the expression of prejudiced attitides. Journal of Abnormal \& Social Psychology, 1959,58, 33-38.

GEEN, R. A. Effects of frustration, attack, and prior training in aggressiveness upon aggressive behavior. Journal of Personality \& Social Psychology, 1968, 9, $316-322$.

GEEN, R. A., RAKOSKY. J. J., \& O'NEAL, E. C. Methodological study of measurement of aggression. Psychological Reports, 1968, 23, 59-62.

ULRICH, R. E., \& AZRIN, N. H. Reflexive fighting in response to aversive stimulation. Joumal of the Experimental Analysis of Behavior, 1962, 5, 511-520.

\title{
The formation of organizational units in free recall learning*
}

\author{
S. I. SHAPIRO and JEROLD A. BELL \\ University of Hawaii, Honolulu, Hawaii 96822
}

Free recall and subjective organization performance were studied as a function of various orders of presentation. Performance was enhanced by the consistent simultaneous or consistent sequential presentation of the members of preestablished high organizational units and by consistent simultaneous presentation of arbitrarily selected low organizational units. Simultaneous but inconsistent presentation of low organizational units impoverished performance.

Tulving (1968) has recently emphasized the importance of describing intraexperimental conditions which influence the formation of subjective organization units in free recall learning. The present study focuses upon whether or not blocked presentation can facilitate recall and subjective organization of unrelated words. Blocking was studied both by comparing simultaneous and sequential presentation of preestablished highly organized pairs, and, within sequential presentation, the number of items interpolated between pair members was systematically varied. In addition, arbitrarily selected low organized pairs were presented either simultaneously or sequentially and either consistently or inconsistently on each trial.

\section{PROCEDURE AND MATERIALS}

A list was composed of 16 words minimally interassociated in terms of free association norms. Of the 240 possible interitem associations, there was only $1(2.7 \%)$. The 16 words comprised eight pairs of words known to be relatively highly subjectively organized by performing an item analysis of subjective organization

\footnotetext{
* Supported by a grant from the University of Hawaii Research Council, and based upon Bell's BA honor's thesis and a report presented at MPA, Cincinnati, April-May 1970
}

units for the data of a previous study. The percentage of the time the eight subjective organization units occurred in the earlier experiment ranged from $6.8 \%$ to $34.7 \%$, with a mean value of $15.3 \%$. The percentages were calculated by dividing the number of occurrences of each organizational pair by the number of times each pair could have been recalled. The word pairs, followed by their percentages of occurrences, were: holes, hold $(34.7 \%)$; eagle, earth $(22.2 \%)$; street metropolis $(14.9 \%)$; table, glass (14.9\%); loud, dream (10.9\%); cheese plain (10.1\%); things, tool $(7.7 \%)$ health, sorrow (6.8\%). The Kucera"Francis (1967) word frequencies of the words ranged from 5 to 244 occurrences per million words.

The same 16 words were employed for eight experimental conditions based on the order of presentation of the words as follows: For Group 1 the members of each highly organized pair were always presented simultaneously, but the order of the pairs (blocks) was randomized on each trial. Presentation for Group 2 was the same as for Group 1 , but instead of the pairs being presented simultaneously, the words were presented sequentially, one by one, as in typical presentations of free recall lists. Presentation for Group 3 was also sequential and similar to
Group 2, except that the pair members were always separated by three randomly intervening words. Presentation for Group 4 was the same as for Group 3, except that the pair members were now separated by seven randomly intervening words. For Group 5, the 16 words were randomized in a different order on each trial, and presentation of the words was sequential. This presentation paradigm is the typical one for free recall experiments and may therefore be considered as a baseline for comparisons. Presentation for Group 6 was the same as for Group 5, but the 1st and 2nd words, 3 rd and 4 th words... 15th and 16 th words on each trial were simultaneously presented. For Group 7, eight pairs of low organized words were arbitrarily selected to be consistently and simultaneously presented, but the order of the pairs (blocks) was randomized on each trial. Presentation for Group 8 was the same as for Group 7, except that the arbitrarily selected pair members were presented sequentially. Thus, Groups 1-4 were presented with the highly organized pairs either simultaneously or sequentially and with zero, three, or seven intervening words between the members of the highly organized pairs. In Groups 5-8, nonhighly organized pairs were presented either simultaneously or sequentially, and these pairs were either consistent or different from trial to trial. For all groups the within-pair serial order of each of the eight preestablished high organization units was always maintained. In the randomizations for Groups 5-8, preestablished pair members were never allowed to appear contiguously; this restriction is necessarily true for Groups 3 and 4 . The mean distance between the high organizational pair members was 4.8 words for Groups 5 and 6 and 4.6 words for Groups 7 and 8 .

For simultaneous presentation, the two members of each pair were located one above the other on a single slide exposed for $2 \mathrm{sec}$ per slide. For sequential presentation each word appeared on a separate slide exposed for $1 \mathrm{sec}$ per slide. The words were randomized on each trial in accordance with the procedures outlined above, and, in addition, repetitions of serial order positions and primacy and recency positions for the words were minimized. Twelve alternating presentation and 60-sec written recall periods were given. Standard free recall instructions were given which emphasized that only the number of words recalled was important and not the order of their recall. The instructions were identical for all groups, and no information was 
Table 1

Mean Performance Averaged Across Trials for Each Group

\begin{tabular}{cccccc}
\hline Group & Recall & (O-E)ITR & $\begin{array}{c}\text { RR* } \\
\text { High Pairs }\end{array}$ & $\begin{array}{c}\text { RR* Consistent } \\
\text { Low Pairs }\end{array}$ & $\begin{array}{c}\text { RR* Changed } \\
\text { Low Pairs }\end{array}$ \\
\hline 1 & 13.13 & 4.62 & .43 & .01 & .01 \\
2 & 12.76 & 3.40 & .26 & .02 & .02 \\
3 & 11.85 & 1.18 & .07 & .03 & .02 \\
4 & 12.02 & 1.54 & .06 & .02 & .03 \\
5 & 12.09 & 1.33 & .05 & .03 & .09 \\
6 & 11.22 & 0.96 & .04 & .03 & .03 \\
7 & 12.20 & 3.20 & .01 & .33 & .02 \\
\hline
\end{tabular}

* Maximum possible $R R$ varies between . jo and .60 for recall of five or more items.

imparted about the orderings of the list to be presented.

\section{SUBJECTS}

The Ss were 240 native English-speaking volunteers from introductory classes at the University of Hawaii. The experimental conditions were randomized in blocks of eight, with 30 Ss assigned per condition. The Ss were tested in groups of two to five individuals. Approximately two-thirds of the $S$ s in each group were females, and no $\mathrm{S}$ had prior experience in a free recall experiment.

\section{RESULTS}

Table 1 summarizes the results of five performance measures. The data were analyzed by means of 8 by 12 (Groups by Trials) analyses of variance, except for subjective organization. Intrusion and duplicate responses were omitted in calculating the measures. All individual comparisons were conducted by means of the Duncan multiple-range test $(\alpha=.01)$. Significant groups and trials effects were found for recall, $F(7,232)=5.25, \quad p<.001$, $F(11,2552)=465.94, p<.001$. Recall was significantly higher for Group 1 than for Groups 3,4,5, and 6, and higher for Groups 2, 7, and 8 than for Group 6. Recall performance for Groups 1 and 2 is probably underestimated on later trials because of ceiling effects for some Ss.

Subjective organization was measured by the index of bidirectional observed minus expected intertrial repetitions, (O-E) ITR (Gorfein, Blair, $\&$ Rowland, 1968). An 8 by 11 (Groups by Successive Trial Pairs) analysis of variance applied to the organization scores resulted in significant groups, trials, and Groups by Trials effects: $F(7,232)=40.92$, $\mathrm{p}<.001 ; \quad \mathrm{F}(10,2320)=100.14$, $\mathrm{p}<.001 ; \quad \mathrm{F}(70,2320)=3.16$, $\mathrm{p}<.001$. Subjective organization was significantly higher for Group 1 than for any other group, and higher for Groups 2 and 7 than for each of the remaining groups. The Groups by Trials interaction primarily reflects the greater increases in organization across trials for Groups 1,2, and 7 relative to the other groups.

The amount of subjective organization specifically based upon the eight pairs preestablished to be highly organized was assessed by regarding these pairs as eight two-member categories and employing the ratio of repetition (RR) to determine the amount of such "category clustering." RR scores were also computed by regarding the low organizational consistently presented pairs as eight two-member categories, and finally, RR scores were computed on the basis of the arbitrarily selected pairs of each trial for Groups 5 and 6 . The results of the three $R R$ analyses of variance and subsequent individual comparisons were: (1) RR scores based upon the high organizational pairs were higher for Group 1 than for any other group, higher for Group 1 than for Group 2, higher for all groups (except Group 6) than for Group 7, and higher for Group 3 than for Group 6; (2) RR scores based upon the low organizational pairs were higher for Groups 7 and 8 than for any other group and higher for Group 7 than for Group 8; and (3) RR scores based upon the arbitrarily selected pairs were higher for Group 6 than for any other group.

\section{DISCUSSION}

The results indicate that subjective organization, and to a lesser extent, recall performance, can be influenced by contiguous blocking of either preestablished highly organized units or arbitrarily selected nonhighly organized units which are consistently and simultaneously presented. The contiguous presentation of highly organized pairs may prime their usage by Ss, and the consistent contiguous presentation over trials may facilitate rehearsal of the same subjective organization units. Performance differences were not obtained as a function of interpolating three vs seven items between the members of preestablished high organizational pairs. It should be noted that the percentages of the high organizational pairs in the present study are typical for the free recall of unrelated lists of words (Bell, 1970). The present results also indicate that when different pairs are arbitrarily selected on each trial and simultaneously presented, recall and organization performance are the poorest of any group. Such an arrangement may engender interference, inasmuch as new subjective organization units are primed on each trial only to be destroyed by the reorganization primed on other trials. Unlike previous studies in which a yoking procedure has been employed (e.g., Mandler \& Pearlstone, 1966), the present experimental paradigm of studying facilitating and interfering effects of organization on recall insures that all Ss are given equal exposure to the recall materials. The utility of the present experimental paradigm has recently been increased by the availability of an extensive normative source of subjective organization units and their frequencies of usage (Bell, 1970). Simultaneous and consistent presentation of low organized pairs also substantially facilitated recall and organization. The latter finding suggests that while Ss may have initial preferences for subjective units of organization, the Ss can effectively make use of other units. The plausibility of this flexibility of organizational units is enhanced by considering the rather low percentage of commonality of subjective organization units typically exhibited in free recall studies (Shapiro, 1970) and the low percentage of subjective organization itself (Bell, 1970). While it is clear that the order of presentation can influence subjective organization, it remains to be determined what the influence of such order effects are relative to the intrinsic properties of the words themselves which comprise subjective units of organization.

\section{REFERENCES}

BELL, J. A. The classification of organizational strategies in free recal learning. Unpublished Master's thesis, University of Hawaii, 1970 .

GORFEIN, D. S., BLAIR, C.. \& ROWLAND, C. The generality of free recall: I Subjective organization as an ability factor. Psychonomic Science, 1968, 11, 279-280.

KUCERA, H., \& FRANCIS, W. N. Computational analysis of present-day American English. Providence, R.I: Brown University Press, 1967.

MANDLER, G., \& PEARLSTONE, Z. Free and constrained concept learning and subsequent recall. Journal of Verbal Learning \& Verbal Behavior, 1966,5 126-131.

SHAPIRO, S. I. The commonality of subjective organization in free recall. Psychonomic Science, 1970, 21, 81-83.

TULVING, E. Theoretical issues in free recall. In $T$. $R$. Dixon and $D$. L. Horton (Eds.), Verbal behavior and general behavior theory. Englewood Cliffs, N.J Prentice-Hall, 1968. Pp. 2-36. 